\title{
LEPROSY LESIONS OF THE FUNDUS OCULI*
}

BY

\author{
E. J. SOMERSET AND N. R. SEN $\dagger$ \\ Calcutta
}

OCULAR manifestations of leprosy constitute a very important aspect of the disease; the loss of vision, leading sometimes to ultimate blindness, may be as serious as any of the other manifestations of the condition. The frequency of ocular involvement appears to vary greatly and estimates of its incidence vary from 10 to 100 per cent., but in Bengal ocular complications are probably less common than in many other parts of the world.

In the non-lepromatous type (" neural" in the Cairo classification, and "tuberculoid" in the Madrid classification), eye lesions are due to the secondary consequences of lagophthalmos-exposure keratitis and its sequelae-and there is no actual leprotic infiltration of the globe; in the lepromatous type the episclera, cornea, and iris may be themselves the site of infiltration with Mycobacterium leprae. These manifestations, episcleral nodules, superficial punctate keratitis, interstitial keratitis, and leprotic nodules of the iris have been described in most surveys of ocular complications.

\section{Previous Investigations}

Although leprotic involvement of the internal organs is known, and involvement of the liver, spleen, testicles etc. have been described and studied post mortem, involvement of the posterior segment of the eye seems to be very rare and descriptions are meagre. According to Duke-Elder (1940), leprous infiltration of the choroid has been observed histologically by Philippson (1893), Wintersteiner (1895), Doutrelepont and Wolters (1896), and Franke and Delbanco (1900). More recently Prendergast (1940) examined 28 eyes histologically and found choroidal lesions in fifteen, in nine of which the bacilli were demonstrated. In no case was there evidence of infiltration of the retina. Some observers have doubted the existence of fundus lesions, but Trantas (1899, quoted by Duke-Elder, 1940) observed punctate nodules similar to those seen in the iris in 68 per cent. of cases, and Rubert (1904) in a systematic search found fundus changes in 47 of 202 cases. Typical pictures of disseminated choroiditis were described by Penichet (1929) and Hoffmann (1928-30) as due to leprosy. However, Harley (1946), examining the fundus in fifty of 150 cases in Panama, found no retinal manifestations, Gibson (1950) found no fundus lesions in 55 white Australians, and Kirwan (1948) stated that he had never seen by ophthalmoscopic examination a lesion in the fundus behind the ora serrata which he considered to be due to leprosy. A similar opinion

* Received for publication August 18, 1955.

+In receipt of a grant from the Indian Council of Medical Research. 
is expressed by de Carvalho (1948), and Aparisi (1950) notes that peripheral choroiditis is occasionally seen but that it is not specific in appearance and its leprotic origin is doubtful. Mendonça de Barros (1939), in an extensive monograph on the clinical aspects of ocular leprosy, does not mention choroido-retinitis.

The most recent work on the subject appears to be that of Elliott $(1948,1949)$ who described in all six cases; he had examined 500 fundi before finding one case of retinal involvement:

In 1947 a lepromatous (L2) case of 15 years' duration had normal fundi but showed four typical "pearls" in the left iris; 8 months later three pearls were present in the iris of the left eye, in different positions from the former four, and the right iris now showed four entirely new pearls. Slight superficial punctate keratitis was present in each eye. Fortunately, the absence of synechia made full dilation of the pupil possible and pearls were now found in the left fundus. These retinal pearls were identical in contour and colour and had the same waxy refractile appearance as those seen in the iris. Most of the pearls were situated near the posterior pole of the eye and were affecting vision. In all, twelve retinal pearls were seen. The right fundus showed no abnormality.

Two years later the pearls in the left fundus were reduced from twelve to seven, and a fresh lesion had appeared in the right fundus which had previously been clear. The patient had been receiving routine promin therapy and there had been no recrudescence of the general leprous condition. Five further cases reported in 1949 showed similar fundus pictures; the pearls were usually behind the equator and associated with evidence of both corneal and iris involvement. In one case, however, the cornea appeared normal and the only sign of iritis was iris pigment on the lens capsule and the posterior surface of the cornea.

\section{Present Investigation}

Material.-The ample material in the Leprosy Department of the School of Tropical Medicine, Calcutta, was kindly put at our disposal by Dr. Dharmendra, the head of the Department. Cases of the lepromatous type were selected and a systematic ophthalmoscopic search was begun.

Method.-The pupils were dilated with homatropine. One of us (N.R.S., a leprologist) selected and classified the cases, and the other (E.J.S., an ophthalmologist) examined the fundi. From March, 1953, four to six cases were selected and examined each week. In the first hundred cases no fundus lesions were found, but the 108th patient appeared to show a genuine example of fundus leprosy. We did not find a second case until a year later we examined the 224 th patient.

\section{Case Reports}

Case 1, an Indian female, aged 46 years, a widow, with no children, had no ocular symptoms. There were no other cases of leprosy in her family, but when she was 14 years old three cases of lepromatous leprosy came to live in her father's house at Mazuffapur, Bihar. At the age of 18 she noticed some loss of sensation of the left thigh with spontaneous blisters which broke down and ulcerated, and hypo-pigmentation on the abdomen. 
She was first seen at the Leprosy Department of the Tropical Diseases Hospital, Calcutta; in 1949 and the following signs were found on examination:

Hypopigmented ill-defined lesions on the body; erythematous and slightly smooth lesions on the body and extremities; diffuse infiltration of the face and extremities; several thickened nerves, especially the right ulnar; anaesthesia of the right hand and right forearm; bacteriological examination from the nose and different parts of the skin revealed Mycobacterium leprae in large numbers.

A diagnosis was made of lepromatous leprosy of moderate extent (L.2.).

She received treatment at another clinic for about 2 years and then discontinued treatment until she returned to the Leprosy Department of the Tropical Diseases Hospital 4 years later in September, 1953. Examination then revealed:

Diffuse infiltration of the face, ears, body, and extremities with nodulation; anaesthesia of the feet, part of the legs, right hand, and part of the right forearm; many thickened nerves. Large numbers of bacilli could still be found. Lepromin test negative.

She was classified L3. No signs of any other disease could be found. Since September, 1953, she had attended the Department and received treatment with sulphetrone. The diffuse infiltration had decreased and the nodulation had completely subsided.

Eye Examination (7.7.53). - There was some loss of hair from the outer third of the eyebrows but the eyelashes were normal. The skin of the lids was included in the generalized lepromatous infiltration of the face. Lid and eye movements were normal. Vision was normal. The conjunctiva and episclera were normal, but both corneae showed typical superficial punctate grey scars in the upper half especially in the upper temporal quadrant. There was no pannus or ciliary congestion. The pupil and iris appeared normal. There were no iris nodules. The left fundus was normal. Examination with the ophthalmoscope showed some nodules in the right fundus (Fig. 1):

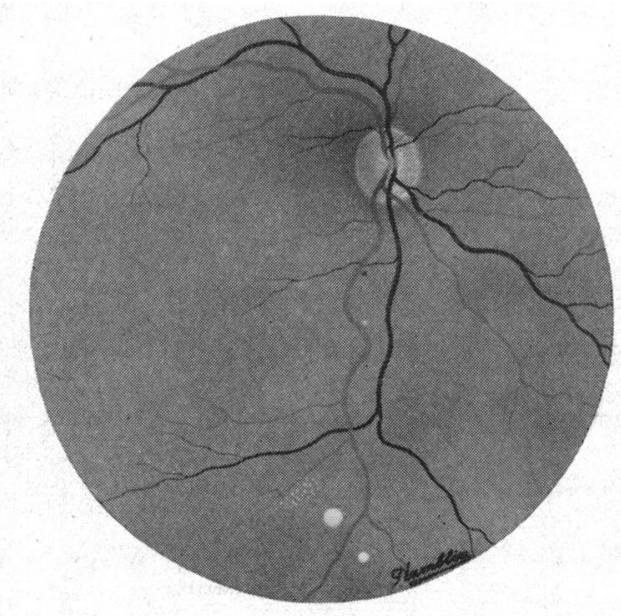

FIG. 1.-Case 1, showing leprous nodules of right fundus.

Two nodules were seen on either side of the inferior temporal branch of the central retinal artery about 5 disc diameters from the disc. The larger was about $0.25 \mathrm{~mm}$. in diameter and was therefore about the same size as the nodules often seen on the iris and typified by those seen in Case 2 (Fig. 2). The surface was bright yellow in colour and the edge well defined. There was no surrounding reaction or pigmentary disturbance. Two patches of minute yellow dots were noted close to the two nodules and another patch near the temporal edge of the disc. No vitreous opacities were observed. The patient was re-examined 5, 7,11, and 13 months later and the retinal condition did not appear to have changed. No iris nodules appeared and her general condition improved. After 20 months the two nodules had vanished leaving behind only the 
faintest discolouration of the retina. Very accurate sketches of the exact position of the nodules had been made, otherwise the faint remaining retinal discolouration would have gone unnoticed. The two patches of minute dots had also faded, leaving hardly any remains.

Case 2, an Anglo-Indian male storekeeper, aged 30, had been born and brought up in Calcutta where he had resided all his life except for 3 years during the second world war. He complained of occasional watering and redness of the eyes for the past 2 years. His father was said to have had leprosy since 1929, when the present patient was 5 years old, and to have died in the Albert Victor Hospital in 1947 at the age of 59, having been blind for the two last years of his life. The patient gave no past history of any other serious illness, but, at the age of 5, lesions had appeared on the skin of the forehead with loss of sensation in that area. In 1940 (when aged 16) he was examined at the Leprosy Department of the School of Tropical Medicine with the following findings:

Loss of sensation in the left hand, part of the left forearm, left foot, and left leg; wasting of the small muscles of the left hand; hypopigmented ill-defined lesions on the forehead, right and left side of the face, back, and buttocks with no loss of sensation; slight erythema of the ears. Bacteriological examination positive and the lepromin test negative.

A diagnosis was made of lepromatous leprosy of moderate extent (L2). He attended for treatment for 3 years until he joined the army in 1943. He saw service in Egypt, Palestine, and Italy and returned to the Department in 1946. His condition was now much worse, the disease was more extensive (L3), and the following further lesions were reported:

Diffuse infiltration and thickening of the face and ears with nodulation; generalized diffuse infiltration of the body and extremities with nodules on the arms and legs; loss of sensation in arms and legs; deformity and wasting of the muscles of the left hand; thickening. of the left ulnar and perineal nerves.

At that time we were examining a series of cases of leprosy mainly to observe corneal and iris conditions and it so happened that this case was included among 150 cases. observed at that time.

Since 1946 the patient has received treatment with sulphetrone and his general condition has much improved, with subsidence of the nodules on the face, ears, and extremities and decrease in diffuse infiltration. The deformities have improved, there has been some return of sensation in the upper arms and legs, and less thickening in the left radial and superficial peroneal nerves, but he is still bacteriologically positive. No signs of any other disease were found.

Eye Examination.-In 1946 there was slight ciliary congestion of each eye. The pupils were round but reacted very sluggishly to light. No keratic precipitates or synechiae were visible on slit-lamp examination. The cornea, lens, vitreous, and retina were normal. The slight redness of the eyes in 1946 disappeared spontaneously during the next few weeks and he had no further trouble till 1952, when slight redness, watering, photophobia, and pain occurred, first in one eye and then the other. These symptoms persisted for a few weeks and then spontaneously subsided. Another attack occurred in December, 1953.

Examination in July, 1954, showed normal eyebrows and lashes and clear corneae. The pupiis reacted very sluggishly and only partial dilation with atropine was possible. The right eye showed three typical iris "pearls" on the surface of the iris at 5,9 , and 11 o'clock, from 0.5 to $1.0 \mathrm{~mm}$. in diameter, yellow in colour, with smooth rounded outlines and homogeneous surface (Fig. 2, opposite). There was no reaction in the surrounding iris and no ciliary congestion, but there was some pigment on the lens capsule and some fine vitreous opacities.

Near the periphery of the fundus there were three nodules, one at 9 o'clock and two at 10 o'clock (Fig. 3, opposite), about one-sixth disc diameter $(0.25 \mathrm{~mm}$.). Their appearance was the same as those seen on the iris; they were round, yellow, homogeneous nodules and appeared to be situated extremely superficially on the retina. Near them in the extreme 

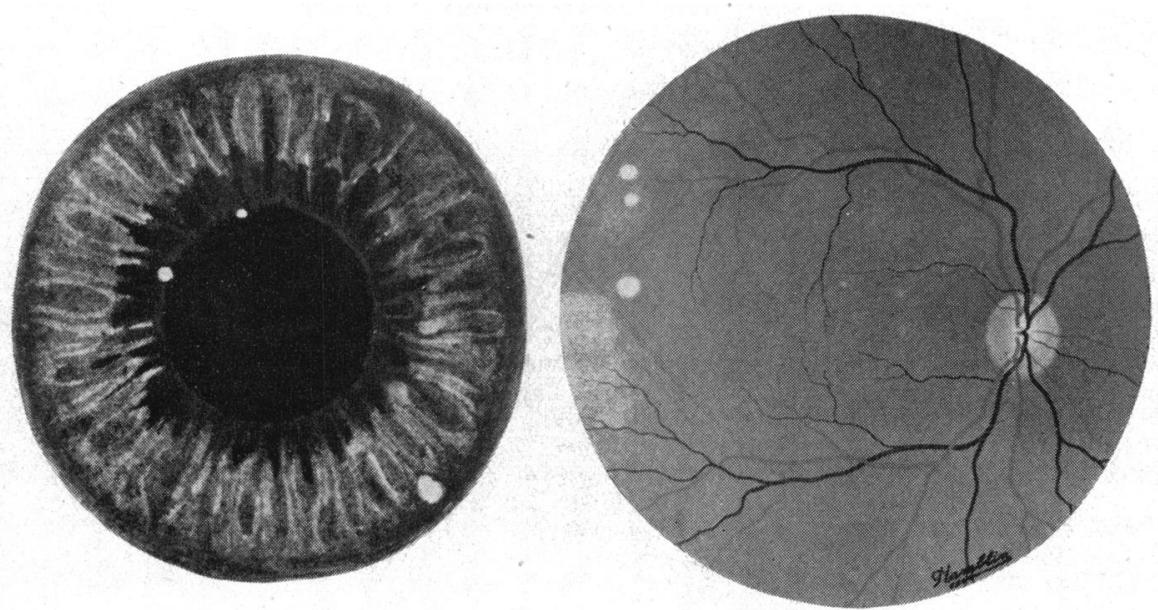

Fig. 2.-Case 2, showing iris " pearls". Fig. 3.-Case 2, showing leprous nodules of right fundus.

periphery, were several mottled yellowish areas which may perhaps have also been due to leprous infiltration, the appearance being not unlike the areas of cystic degeneration sometimes seen at the extreme periphery of the retina in normal eyes. Unfortunately, pupil dilation was not sufficient for the fundus nodules to be examined with the slit lamp.

The left eye showed some small posterior synechia and a nodule in the iris at 5 o'clock near the periphery. Pupil dilation of this eye was not as great as in the right and only a partial view of the fundus was possible; no nodules could be seen, but fine vitreous opacities were present. On August 20,1954, some 5 weeks later, the right eye showed a change in the iris nodules. The nodule at 9 o'clock had disappeared but at 11 o'clock there were now two nodules instead of one. The fundus picture of the right eye had not changed.

The left iris now showed an additional minute nodule at 11 o'clock, midway between the periphery and the pupil margin. Fundus details of this eye could not be seen.

In November, 1954, there was little change in the right eye, in either iris or fundus, but a further nodule had appeared in the left iris at 4 o'clock.

In January, 1955, 6 months after the first iris and retinal nodules were seen, the nodules in the right iris had absorbed (except for some faint remains at 11 o'clock) but there was little change in the fundus picture, the three nodules being still present, though possibly slightly smaller. The left iris showed some absorption of the iris nodules, which were now only just visible.

\section{Summary}

Two patients with lepromatous leprosy, one male and one female, had had the disease for at least 25 years. One had had mild symptoms of iritis off and on for about 8 years and showed a very mild iritis with typical iris "pearls" but no involvement of the cornea. The other showed corneal scars from previous leprotic superficial punctate keratitis but no evidence of previous iritis. Neither case had symptoms related to the retinal involvement. The retinal lesions were exactly the same as those seen in the iris, namely, the small nodules or pearls about $0.25 \mathrm{~mm}$. in diameter. No surrounding reaction or pigmentary disturbance was seen. The extreme 
chronicity of the eye lesions even during treatment is characteristic.

Our thanks are due to Dr. Dharmendra of the School of Tropical Medicine, Calcutta, for permission to examine the cases and for much help and advice.

\section{REFERENCES}

APARISI, T. (1950). Arch. Soc. oftal. hisp.-amer., 10, 107. (Abs. (1950). Ophthal. Lit. (Lond.), 4, p. 449, No. 1862).

De Carvalho, J. Siqueira (1948). Rev. brasil. Oftal., 7, 31. (Abs. (1948), Ophthal. Lit. (Lond.), 2, p. 545, No. 2219).

Doútrelepont and Wolters, M. (1896). Arch. Derm. Syph. (Wien), 34, 55.

DUKE-ELDER, S. (1940). "Text-book of Ophthalmology", vol. 3, p. 2320. Kimpton, London.

Elliotr, D. C. (1948). Int. J. Leprosy, 16, 347. (1949). Ibid., 17, 229.

Franke, E., and Delbanco, E. (1900). v. Graefes Arch. Ophthal, 50, 380.

Gibson, J. B. G. (1950). Med. J. Aust., 1, 8.

Harley, R. D. (1946). Amer. J. Ophthal., 29, 295.

HofFMANN, W. H. (1928). Z. ImmunForsch., 59, 297. (1928). Derm. Wschr., 86, 394.

(1929). J. trop. Med. Hyg., 32, 328.

(1930). J. Clin. (Rio de J.), 11, 225. All cited by Duke-Elder, (1940).

KIRWAN, E. W. O'G. (1948). Trans. roy. Soc. trop. Med. Hyg., 41, 583.

MENDONÇA De BARRos, J. (1939). "Aspectos clinicos do comprometimento ocular da lepra". Quarta Monografia dos Arquivos Santorio Padre Bento. Companhia Melhoramentos, Sào Paolo.

PeniCHeT, J. M. (1929). Rev. cubana Oftal., 1, 320.

PhilipPson, L. (1893). Beitr. Augenheilk., 2, (Heft 11), p. 31.

Prendergast, J. J. (1940). Arch. Ophthal. (Chicago), 23, 112.

RUBert, J. (1904). Mitt. Augenklinik v. Fejer., 2. Cited by Duke-Elder, 1940.

Trantas (1899). Bull. Soc. franc. Ophtal., 17, 275.

WINTERSTEINER (1895). Wien klin. Wschr., 8, 350. 